\title{
Preservice Teachers' Use of Computational Thinking to Facilitate Inquiry-based Practical Work in Multiple-deprived Classrooms
}

\author{
Maria Tsakeni ${ }^{1^{\star}}$ \\ ${ }^{1}$ University of the Free State, SOUTH AFRICA \\ Received 5 May 2020 • Accepted 27 November 2020
}

\begin{abstract}
Inquiry-based practical work (IBPW) is one of the innovative instructional strategies in science education. Science teacher preparation programmes play a role in preparing preservice teachers to facilitate IBPW in classrooms located in different school settings, including multiple-deprived classrooms. The adverse conditions against the successful implementation of IBPW found in multiple-deprived classrooms provide problems that preservice teachers will have to solve in their future classrooms. It is against this background that this study explored how preservice science teachers used computational thinking as a problem-solving strategy when facilitating IBPW in multiple-deprived classrooms. Using a single-case exploratory study, the experiences of 16 preservice physical sciences teachers were elicited through lesson planning, simulated teaching, and reflection. The data collected were analysed through thematic-content-analysis techniques. Findings indicate how through the use of computational thinking, participants were able to solve problems that had the potential to inhibit the implementation of IBPW.
\end{abstract}

Keywords: computational thinking, inquiry-based practical work, multiple-deprived classrooms, physical sciences, preservice teachers

\section{INTRODUCTION}

Computational thinking is considered a $21^{\text {st }}$ century skill that should be developed through schooling because of its potential to aid problem-solving. Although Mouza et al. (2017) posited that there is no single widely accepted definition of computational thinking, Wing's (2006) definition seems to be used extensively (Kazimoglu et al., 2012). According to Wing $(2017$, p. 8), "[c]omputational thinking is the thought processes involved in formulating a problem and expressing its solution(s) in such a way that a computer-human or machine-can effectively carry out." Therefore, computational thinking can be used as a problemsolving strategy in many real-life situations. Wing (2017) further called for the development of computational thinking skills to be one of the educational goals in the $21^{\text {st }}$ century. This call makes sense considering that digital and computer technologies are increasingly becoming part of everyday life. The call has implications for schooling and teacher preparation. Yadav, Stephenson, and Hong (2017) posited that preservice teachers should be prepared to integrate computational thinking in their future classrooms and different subject areas. Evidently, computational thinking stands as a useful strategy when engaging learners in problemsolving.

Innovative instructional strategies sometimes stem from broader educational innovations that target outcomes related to societal needs. These outcomes include the development of $21^{\text {st }}$ century skills and the preparation of citizens who will constitute the workforce for the economic-growth aspirations of countries and those with knowledge and skills for promoting sustainable development. Printy (2010) pointed out that through the use of national standards, such as highstakes tests, it is possible to find out whether learners have opportunities to learn by gaining insights on how learners gain access to curricula. Hence, in the case of educational outcomes (learners' knowledge and skills) aligned to societal needs, it is important to ensure that learners are exposed to opportunities to learn. The use of appropriate instructional strategies becomes pivotal in ensuring that learners have access to innovative

(c) 2021 by the authors; licensee Modestum. This article is an open access article distributed under the terms and conditions of the Creative Commons Attribution License (http://creativecommons.org/licenses/by/4.0/).

mtsakeni@gmail.com (*Correspondence) 


\section{Contribution to the literature}

- This paper contributes to literature on preservice physical sciences teachers' conceptions of conditions of classroom multiple deprivation for IBPW, showing that some of these problems can be solved through the use of computational thinking strategies.

- The study provides a useful way of integrating computational thinking in science-methods courses for preservice teachers to begin to develop important beliefs and perceptions that they will use in their future classrooms.

- The study contributes to the literature that shows the interconnectedness between inquiry-based science and computational thinking, showing that the two can be mutually inclusive.

curricula. However, many learners are denied access to innovative curricula because teachers fail to use the appropriate instructional strategies, such as inquirybased practical work (IBPW) in science classrooms. Kidman (2012) reported that in Australia, teachers were not yet ready to implement an inquiry-based science curriculum, citing adverse conditions that had to do with lack of content knowledge, materials, behaviour management, and classroom space. Similarly, in South Africa, Ramnarain, and Hlatswayo (2018) noticed that although teachers have positive beliefs and perceptions about inquiry-based learning, its implementation is hindered by difficulties posed by lack of resources, large classes and limited time to complete curricula. The above mentioned and other impediments to inquiry-based teaching and learning pose as conditions of multiple deprivation for IBPW in science classrooms. The concept of multiple deprivation was developed so that adverse conditions in society and in this study as applied to science classrooms become measurable to avoid merely describing them as challenging situations (Maringe, Masinire, \& Nkambule, 2015).

This study assumed that IBPW is sometimes considered difficult to implement in science classrooms. The situation is exacerbated by acute shortages of material resources and unfavourable teacher professional identities (Kim \& Tan, 2011). However, teacher training programmes are responsible for preparing preservice teachers in knowledge domains for science-classroom practice and contribute to the development of effective professional identities. Shulman (1987) framed the knowledge domains that teachers use in classroom practice as pedagogical content knowledge (PCK). Similarly, Magnusson, Krajcik, and Borko (1999) framed specific knowledge domains for science teaching. Mulhall, Berry, and Loughran (2003) added that teachers need the knowledge related to school contexts of difficulties/limitations and other influencing factors when teaching specific content in science. Cheng, Talib, and Othman (2016) asserted that teachers need to develop perceptions to drive the process of teaching and learning. In this study, the difficulties/limitations and other influencing factors are considered to be conditions of multiple deprivation. An assumption was made that preservice teachers are equipped with knowledge of these factors in methods courses and practicum experiences. Another assumption was made that as preservice teachers overcome the difficulties connected to the use of IBPW in science classrooms, they will engage in problem-solving. Hence, the study adopted a computational thinking conceptual framework to explore how preservice physical sciences teachers make IBPW accessible to learners in multiple-deprived classrooms. The study contributes to literature on preparing preservice science teachers in the use of IBPW and computational thinking for multiple-deprived classroom environments. The main question for this study is: How do preservice physical sciences teachers use computational thinking to solve problems associated with the implementation of IBPW in multiple-deprived classrooms? The main research question was supported by the following subsidiary questions: (i) How do the preservice teachers describe conditions of multiple deprivation in physical sciences classrooms? (ii) Which instructional strategies are used by the preservice teachers to integrate computational thinking and IBPW in multiple deprived classrooms? and (iii) What are the preservice teachers' emerging beliefs and perceptions on computational thinking integration in physical sciences classrooms?

\section{LITERATURE}

\section{Computational Thinking and Preservice Science Teacher Preparation}

Given the background of an increasing recognition that computational thinking is a problem formulation and solving tool, Wing (2017) observed that there is a steady increase in the incorporation of computational thinking skills development in undergraduate courses and other disciplines. Similarly, it is posited that science is increasingly becoming a computational thinking endeavour (Weintrop et al., 2016) and teachers need to be prepared accordingly. One way of bringing computational thinking to schools is by making sure that computational thinking is taught in methods courses for preservice science teachers (Weintrop et al., 2016; Yadav et al., 2017). In this regard, Hestness et al. (2018) said that the preparation of preservice teachers may also be done 
by mentor teachers who would have gone through professional development on how to infuse computational thinking in science classrooms. However, Mouza et al. (2017) observed that very few teachers possess the skills to embed computational thinking in their classrooms. Few initiatives are currently in place to prepare preservice teachers in the facilitation of computational thinking through the subjects that they teach.

Yadav et al. (2017) observed that in terms of preparing teachers to facilitate computational thinking for learners, a few in-service teacher programmes have been conducted. Based on the potential growth of computational thinking and a belief that it is a skill to be possessed by ordinary citizens in the $21^{\text {st }}$ century, preparing preservice teachers in this regard needs to be seriously considered. To this end, Yadav et al. (2017) proposed the redesign of educational technologies and methods courses. Similarly, Mouza et al. (2017) designed an educational-technology course for preservice teachers to be incorporated in K-8 settings. The course positively influenced some preservice teachers' knowledge of concepts, tools, and practices in computational thinking. Yadav et al. (2017) pointed out that although computational thinking is connected to programming, it is not necessary for preservice teachers to learn programming. Thus, the computational thinking concepts of problem identification, problem decomposition, algorithm, debugging, data, abstraction, query, sensing and feedback, iterations, and systems can be integrated into methods courses in preservice teacher education.

To add to the contributions made by the studies mentioned above, this study explored the use of computational thinking as a teaching strategy and as a tool for problem-solving in the science classroom characterised by multiple-deprived conditions. According to Wing (2017), computational thinking is the process of engaging in thought processes that result in the formulation of a problem and expressing its solutions. Literature indicates that the implementation of IBPW is fraught with challenges (Kim \& Tan, 2011; Kidman, 2012; Ramnarain \& Hlatswayo, 2018). For this study, these challenges are regarded as unmet needs resulting in multiple-deprived classrooms (Noble et al., 2013). The unmet needs in multiple-deprived classrooms that stand in the way of the implementation of innovative instructional strategies present real-life problems that preservice science teachers should be equipped to solve.

At face value, multiple-deprived classrooms in South Africa may be associated with schools that are disadvantaged, such as those in townships, farms, and rural areas (Chikoko, 2018). However, multipledeprived classrooms may extend to other, supposedly advantaged contexts in terms of socio-economic status, such as when teachers fail to implement innovation- aligned teaching strategies (Tsakeni, 2018). Employing computational thinking involving the use of computers and similar gadgets for preservice teachers to implement IBPW comes against a background in which information and communications technologies are reportedly integrated into classrooms to support teacher-centred strategies in mundane communication and administrative routines in some parts of South Africa (Ndlovu \& Meyer, 2019). In this study, computational thinking is purposely integrated into IBPW as way of ensuring that educational technologies are used in meaningful ways that engage learners, through a methods course for preservice teachers.

\section{Computational Thinking for Science classrooms}

Wing (2017) considered computational thinking as a problem-solving skill that needs to be possessed by citizens of the $21^{\text {st }}$ century. Computational thinking as espoused by Wing $(2006,2017)$ involves the use of machines and digital technologies and tools. Yadav et al. (2017) mentioned nine core computational thinking concepts and capabilities. These are data collection, data analysis, data representation, problem decomposition, abstraction, algorithms, automation, parallelisation, and simulation. The authors further indicated that some of the processes involved in computational thinking are practised by learners in science through some scientificinquiry methods when they engage in process skills such as collecting, presenting and analysing data from experiments. However, Weintrop et al. (2016) mentioned that the use of computational thinking in science and mathematics can be placed in four major categories which are: (i) data practices, (ii) modelling and simulation practices, (iii) computational problemsolving practices, and (iv) systems-thinking practices. The integration of computational thinking in science and other science, technology, engineering and mathematics (STEM) disciplines supports the development of digital and computer science literacies (Djambong \& Freiman, 2016) required by citizens of the $21^{\text {st }}$ century. IBPW is one form of inquiry-based learning that allows learners to engage in computer-based activities in addition to hands-on activities (Akuma \& Callagan, 2019). Dunn and Ramnarain (2020) observed the use of interactive computer-simulation-supported inquiry to improve the studied South African Grade 8 learners' conceptual understanding of atoms and molecular structures. This increasing recognition of computational thinking skills is concomitant with the increasing presence of digital and computer technologies in people's everyday lives. There are implications for incorporating computational thinking in schooling and one of them is the drive to prepare preservice teachers accordingly. The integration of computational thinking and IBPW allows preservice teachers to make use of educational technologies in meaningful and engaging ways for learners. 


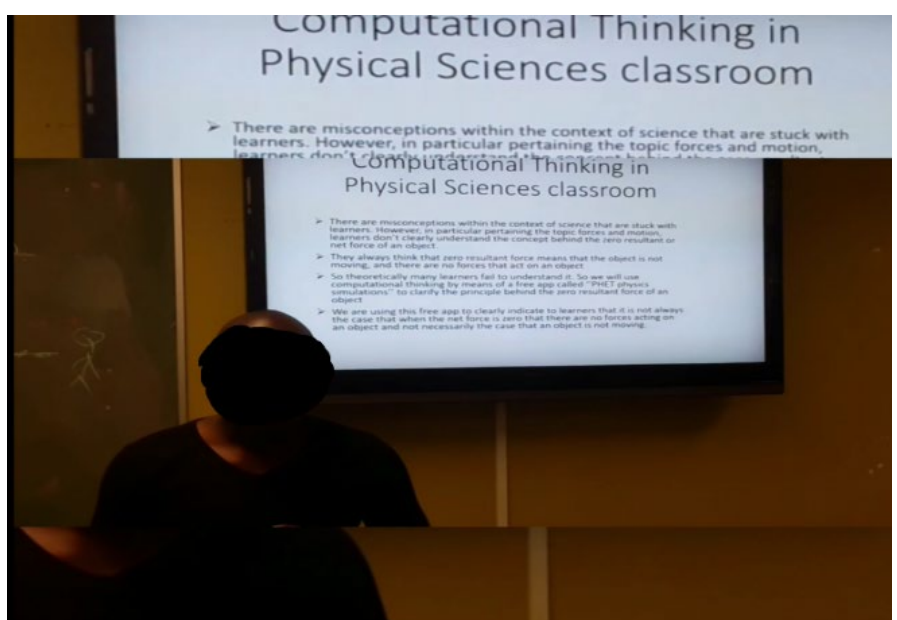

(a)

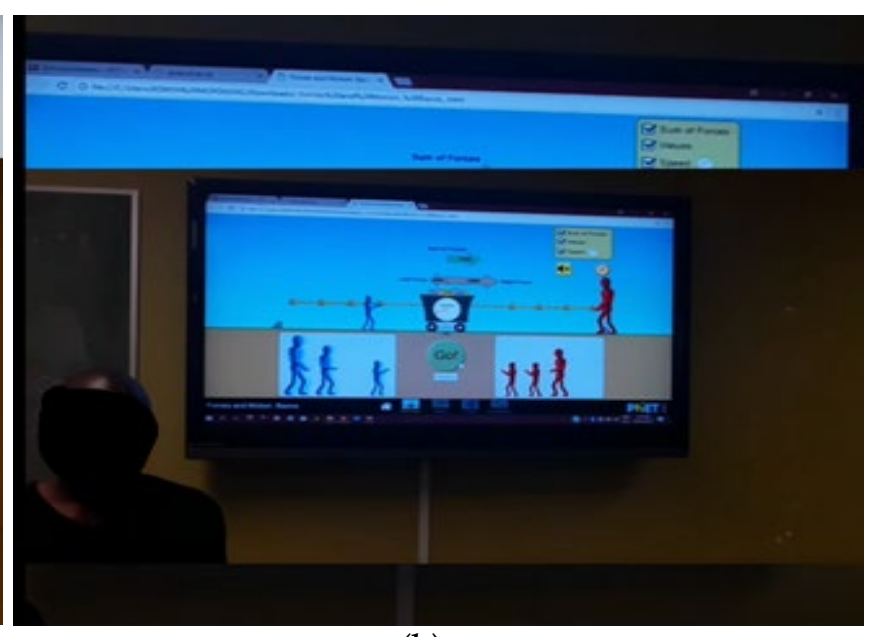

(b)

Figure 1. a) Presentation on identifying a learning problem; b) use of PhET simulation to solve the learning problem

\section{METHODS AND STUDY CONTEXT}

The study's aim was to explore how preservice teachers develop computational thinking skills for solving some identified problems in the implementation of IBPW in multiple-deprived classrooms. The study is part of a larger research project that makes use of designbased research and action research (Andriessen, 2007). Accordingly, the research design of the larger research project consists of ten steps (five for design-based research and five for action research). The steps are ordered in such a way to start with three design-based procedures (theorising, agenda setting, and [re]designing). This, according to Andriessen (2007), is followed by five action-research procedures (diagnosing, action planning, action taking, evaluating, and specifying learning) and, lastly, by two designbased research procedures (reflecting and developing knowledge).

\section{Research Methods}

This particular study is situated in the actionplanning and action-taking stage of the design-based research through an explorative qualitative single-case study of one university, guided by an interpretive paradigm. An interpretive research paradigm allows for meaning-making based on how the participants understand the phenomena under study (Thanh \& Thanh, 2015). The process of action planning and action taking was embedded in the study in two ways. On one side, the researcher identified a problem in the workplace in line with action research, where actions are closely associated with the solving of problems (Collato et al., 2018). The workplace problem was located in the transformation agenda of the participating university's education faculty. Specifically, it was on how the methods courses prepare preservice teachers to implement innovative instructional strategies in classrooms that are increasingly permeated by digital and computer technologies. On the other side, data were generated as a result of the participating preservice teachers identifying a problem in physical sciences classrooms and engaging in formulating a solution through action planning and action taking.

\section{Sampling}

Based on the above, the specially designed reflection and lesson-planning tool described in the next section was administered to 16 preservice teachers before leaving for a 12-week teaching-practice placement. The 16 preservice teachers (8 Bachelor of Education [BEd] and 8 Post-Graduate Certificate in Education [PGCE] students) were conveniently sampled from a larger group of 38 because they had consented to participate in the study. The participants were considered to be datarich because they had participated in the computationalthinking-infused course described in the next section.

\section{Data Collection through Lesson Design, Simulated Teaching and Reflection}

In order to conduct the action-planning and actiontaking stage of the design-based study, a physical sciences methods course infused with computational thinking was taught to final-year preservice teachers in the BEd and PGCE programmes through a two-week module which was 120 minutes $x$ two sessions long. The preservice teachers were composed of 18 final-year BEd and 20 PGCE students in a physical sciences education teacher-training programme. Figure 1 shows pictures of one of the presenters illustrating how to use computational thinking in dispelling the misconceptions that learners display on the concept of resultant force under the topic of forces and motion.

The participants had no background of computer science and therefore it was important to begin by defining and explaining computational thinking. Finally, a groupwork activity was conducted in which 
Table 1. Excerpt from the lesson plan and video of simulated teaching codebook

\begin{tabular}{llll}
\hline Code & Description of code & Example from lesson plan excerpt & Category \\
\hline $\begin{array}{l}\text { Defining an IBPW teaching } \\
\text { and learning problem } \\
\text { (problem identification, } \\
\text { problem decomposition) }\end{array}$ & $\begin{array}{l}\text { - Learner misconceptions } \\
\text { - Lack of materials to } \\
\text { facilitate IBPW }\end{array}$ & $\begin{array}{l}\text { Labs and experiments often require } \\
\text { science teachers to spend a lot of time } \\
\text { for preparation and set up }\end{array}$ & $\begin{array}{l}\text { Conditions of multiple } \\
\text { deprivation formulated } \\
\text { as a problem }\end{array}$ \\
\hline $\begin{array}{l}\text { Integration of computational } \\
\text { thinking in IBPW activities } \\
\text { (algorithm, problem-solving) }\end{array}$ & $\begin{array}{l}\text { Instructional strategies } \\
\text { used }\end{array}$ & $\begin{array}{l}\text { Using this app, learners will be able to } \\
\text { perform experiments and manipulate }\end{array}$ & $\begin{array}{l}\text { Instional strategies } \\
\text { variables that they want to use, record computational thinking } \\
\text { cosults, and draw conclusions with just and IBPW }\end{array}$ \\
& & $\begin{array}{l}\text { a click of a mouse } \\
\end{array}$
\end{tabular}

Table 2. Excerpt from the reflections codebook

\begin{tabular}{llll}
\hline Code & Description of code & Example from lesson plan excerpt & Category \\
$\begin{array}{l}\text { What the preservice teachers } \\
\text { learnt about computational } \\
\text { thinking and IBPW integration } \\
\text { (abstraction) }\end{array}$ & $\begin{array}{l}\text { Descriptions of specific } \\
\text { instructional and/or } \\
\text { problem-solving strategies } \\
\text { for IBPW through the use } \\
\text { of computational thinking }\end{array}$ & $\begin{array}{l}\text { As teachers, we should be resourceful } \\
\text { and not rely on a single method of } \\
\text { teaching, but we can use other methods, } \\
\text { such as computational thinking, to }\end{array}$ & Beliefs \\
$\begin{array}{l}\text { Judgements on the value of } \\
\text { computational thinking } \\
\text { integration (abstraction) }\end{array}$ & $\begin{array}{l}\text { Expressions of advantages } \\
\text { and disadvantages of using } \\
\text { computational thinking }\end{array}$ & $\begin{array}{l}\text { But, we can say that the application } \\
\text { really needs some improvement. We } \\
\text { are saying this because the application } \\
\text { does not interpret or analyse the results. }\end{array}$ & Perceptions \\
& & &
\end{tabular}

the participants formulated classroom-practice problems for IBPW implementation in a way that computational thinking could help to solve the problems. Each group presented the work done to the rest of the class, thereby generating more reflections and discussions. After the teaching of the course was completed, the participants were expected to transfer the knowledge and skills acquired in solving the problems encountered in physical sciences classrooms during practicum. When the participants returned to campus at the end of a three-month-long practicum period, they were divided into four groups of four members each, two groups each for the BEd and PGCE groups, respectively. The groups were asked to design an IBPW activity (lesson planning) in which computational thinking was used to solve the identified problem based on the following open-ended instructions:

(1) Identify a problem in the facilitation of IBPW in the physical sciences classroom that you can solve through computational thinking.

(2) Design an activity in which you will facilitate for learners to solve either chemistry or physics problems through computational thinking by means of digital tools.

(3) Reflect on your experiences on the use of computational thinking when facilitating IBPW.

(4) Submit your report (lesson plan and reflection) and a 20-minute-long video of simulated teaching to illustrate your design.

Participants thus submitted the lesson plans, videos of simulated teaching and reflections which contained the emerging beliefs and perceptions on the use of computational thinking to solve IBPW-implementation problems. Tables 1 and 2 show how the data collected were coded.

\section{Data Analysis}

The lesson plans, transcripts of the video-recorded presentations, and the reflections were analysed for content that fitted in three predetermined themes. Accordingly, pieces of data were coded and the codes were grouped in categories which were further bunched together into bigger groups called themes. The themes were informed by the findings by Hestness et al. (2018), where teachers who participated in a professional development to integrate computational thinking in science education displayed three forms of knowledge. First, the teachers possessed pre-existing knowledge of learners, the curriculum and school contexts; second, they made connections between the new content and the pre-existing knowledge; and third, they developed new understandings after the intervention. Accordingly, the three themes that guided the data analysis process are: (i) conditions of multiple deprivation formulated as a problem, (ii) instructional strategies for integrating computational thinking and IBPW, and (iii) emerging beliefs and perceptions on computational thinking. The use of four-membered groups and multiple groups $(n=4)$ ensured the capturing of co-constructed rich insights and triangulation of data. The methods course intervention infused with computational thinking was a way to ensure credibility and trustworthiness of the findings.

\section{FINDINGS}

The findings of the study are presented under the three themes, which are (i) conditions of multiple 
deprivation, (ii) instructional strategies for integrating computational thinking and IBPW and (iii) emerging beliefs and perceptions on computational thinking.

\section{Conditions of Multiple Deprivation Formulated as a Problem}

Each of the four groups described conditions of multiple deprivation by way of formulating them as problems that hindered the implementation of IBPW in physical sciences classrooms. The problem formulation for each of the groups is described next.

Group 1 identified the lack of laboratory materials and facilities as a hindrance to the implementation of IBPW and the achievement of some science teaching and learning objectives. A reflection excerpt by Group 1 reads as follows:

Science cannot be meaningful to learners without worthwhile practical experiences in the school laboratory. Unfortunately, many schools do not have enough materials in the laboratory and this leads to negligence of practical work. Some of the objectives will be met through theory, but some will require one to perform the experiment. Therefore, they will not be met due to lack of materials needed for this particular experiment.

To illustrate their point, Group 1 identified lesson objectives, including some that could not be achieved without engaging learners in practical work when teaching Boyle's law. The lesson objectives were as follows:

\section{To learn SI units for pressure and volume}

2. Define Boyle's law

3. Describe the relationship between volume and pressure for a fixed amount of a gas at constant temperature (Boyle's law)

4. Learners should be able to represent Boyle's law graphically

5. Be able to do calculations using Boyle's law

6. Learners will gain process skills: measuring, represent data, computer skills

Objectives 4 and 6 would not be achieved without engaging learners in hands-on or computer-based practical-work activities. The group further reflected as follows:

Although learners can define Boyle's law by describing the relationship between volume and pressure, they cannot actually represent it graphically. This is because in order to represent data graphically, you need to have both values for the $\mathrm{Y}$-axis and the $\mathrm{X}$-axis, which requires one to measure using the Boyle's apparatus for this particular experiment.
The excerpt above shows that the group developed the lesson plan and they engaged in problem decomposition by pinpointing a teaching and learning problem that may arise due to the lack of laboratory materials and facilities when teaching Boyle's law. The group indicated that although learners may be able to describe the relationship between volume and pressure, they may not be able to verify this relationship or represent the relationship on graphs if they do not have the data (corresponding values of volume and pressure).

Based on the notion that computational thinking can be a way of integrating human thinking and computer capabilities, Group 2 formulated a problem in which they would use IBPW activities to teach learners computational thinking. The group hoped that the teaching of the computational thinking processes would help learners to understand the abstract relationship between speed and force. The group reflected that, " $t \mathrm{t}] \mathrm{he}$ importance of computational thinking is to think about data, ideas, using and combining these resources to solve problems." The group suggested facilitating problem decomposition, pattern recognition, pattern generalisation and abstraction and algorithm design for learners.

Group 3 formulated a problem related to time constraints and the high costs of laboratory materials and equipment as factors that impede the proper implementation of IBPW. The group reflected as follows:

Labs and experiments often require science teachers to spend a lot of time for preparation and set up. Many experiments in the labs cannot be completed in less than 50 minutes. Some, if not all, science lab equipment cost a lot of money and budget concerns may limit teachers from doing certain experiments. In our case, hypothetically speaking, the school has no materials for the heating and cooling curve of water experiment.

Similar to Groups 1 and 3, Group 4 identified the condition of multiple deprivation as the lack of materials in science classrooms and the high costs associated with buying and replacing materials. In addition, the group indicated that some measuring equipment are easily damaged in the laboratories, resulting in inaccurate measurements. The group said:

Science practicals [work activities] require trial and error in order to achieve accurate results. In our schools, the science laboratories are underresourced. This results in inaccuracies of results during practical experiments. The electrical components are expensive and they are very fragile. One mistake of overvoltage can damage the components and thereby cause inaccurate results. This is one of the reasons why some of the schools have little or no appropriate electrical components. Materials like batteries get used up 
during a practical, causing results not to be accurate and hinders learners to do multiple trials.

The multiple-deprivation conditions mentioned by the groups were related to lack of material resources and time constraints resulting in the formulation of problems associated with limited access to IBPW learning experiences in classrooms. The groups were able to decompose the problems identified in the context of teaching particular topics. Some decomposed problems included the realisation that (i) some lesson objectives could not be achieved if learners did not engage in IBPW activities, (ii) some concepts remain abstract to learners if they do not engage in IBPW, (iii) some IBPW activities require a lot of preparation time, and (iv) some measuring equipment are easily damaged and give inaccurate measurements. The next section discusses some of the solutions to the identified problems through computational thinking integration.

\section{Instructional Strategies for Integrating Computational Thinking and IBPW}

Group 1 suggested that they would compensate for the lack of laboratory materials and facilities by making use of a virtual, online laboratory which offers immersive and interactive 3D-simulation experiences of a real laboratory for learners. The group reflected as follows:

In order to solve this problem, we will use a virtual lab called PraxiLabs. It is targeted for everyone, whether high [school] scholars, undergraduates, etc. This lab provides students with an immersive and interactive 3D simulation of a realistic lab, enhancing their understanding and knowledge with a virtual hands-on experience of what they've learned.

To circumvent the lack of materials for hands-on laboratory activities, the group suggested the use of virtual hands-on activities. The group reflected further:

It [PraxiLabs] is an online lab that can be accessed by anyone with a computer, tablet, smartphone, etc. In order to access this lab, a teacher has to create a profile with personal login details. Using this app, learners will be able to perform experiments they want and manipulate the materials and variables that they want to use, record results and draw conclusions with just a click of a mouse. This app is user friendly and it minimises human errors.

Group 2 decided to teach computational thinking when investigating the relationship between SPEED and FORCE through virtual hands-on activities using a PhET simulation application. The group considered the concept to be abstract and therefore suggested an instructional strategy that engages learners in computational thinking as subsequently described.

\section{Problem decomposition}

The group decomposed the problem that led to the abstractness of the concept by pointing out the absence of an equation that directly links speed and force. The group reflected as follows:

The project is about determining the relationship between speed and the applied force. We cannot directly link the speed known as velocity in its vector form with force in the same equation. That is why the link between the two values is through ACCELERATION.

\section{Pattern recognition}

The group suggested the use of pattern recognition as a way of facilitating that learners establish the relationship between speed and force using the set of relationships in the equations below:

Equation 1: SPEED $=\frac{\text { DISTANCE }}{\text { TIME }}$

Equation 2: ACCELERATION $=\frac{\text { VELOCITY }}{\text { TIME }}$

Equation 3: $F O R C E=M A S S \times$ ACCELERATION

Using the relationships above, Group 2 explained how they would facilitate for learners to see that an increase in acceleration triggers an increase in velocity. The group reflected:

We recognise from the given equations that velocity is directly proportional to acceleration, according to equation $2[\mathrm{a}=\mathrm{v} / \mathrm{t}]$, which gives $\mathrm{a}$ direct definition of what acceleration is. We also know from Newton's second law that $\mathrm{F}=\mathrm{ma}$, where force is in direct proportionality to acceleration. Therefore, a pattern is recognised between force and acceleration as well as between acceleration and velocity, which simply shows that when you increase your applied force, it will impact on your acceleration and increases it as well.

\section{Pattern generalisation and abstraction}

The group suggested a statement that would describe the relationship between speed and force through pattern generalisation and abstraction: "Force is directly proportional to velocity. An increase in force commences an increase in velocity. A decrease in force directs a decrease in velocity as well."

\section{Algorithm design}

Group 2 designed five algorithmic steps that learners would follow when using the PhET simulation (Figure 2): 


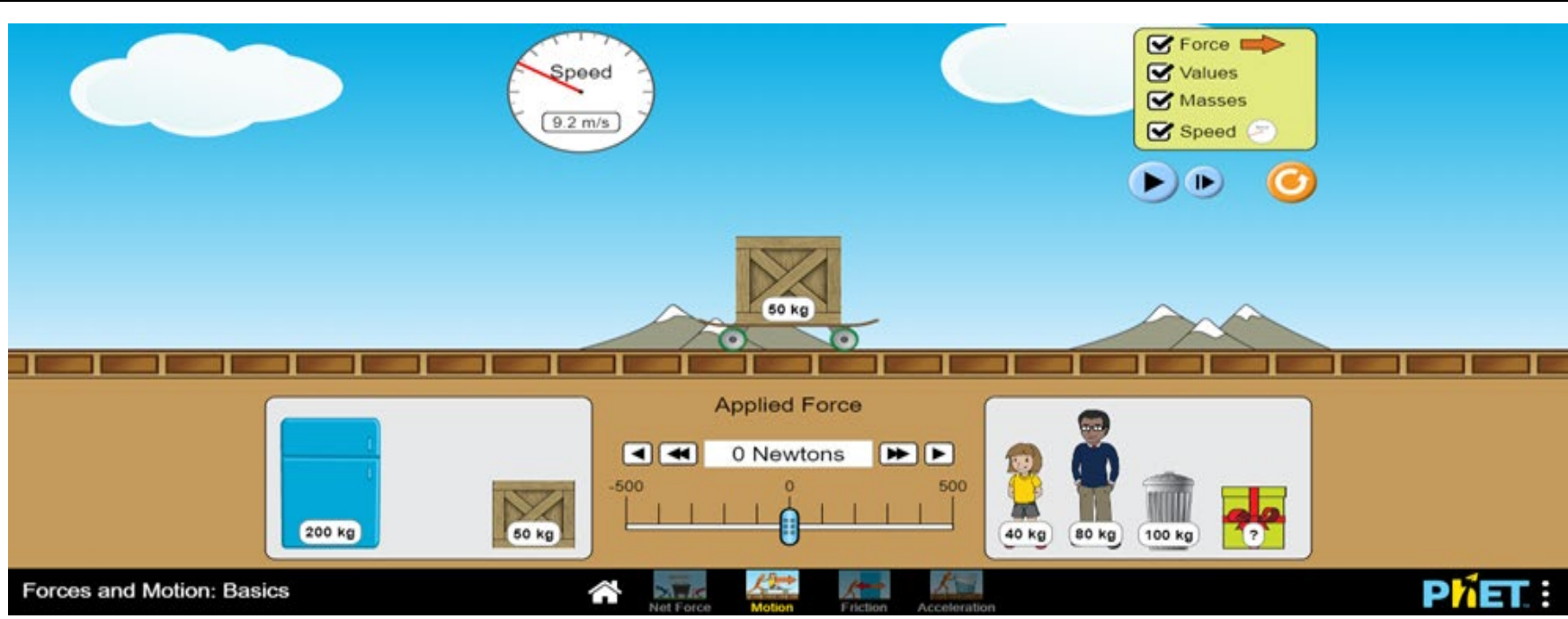

Figure 2. PhET simulation on force and speed experiment

1. Show masses.

2. Show speedometer.

3. Change force and take readings.

4. Check the change in the speedometer as the force is changed.

5. Conclude based on the motion seen.

Group 3 proposed to use the CK-12 simulation application because they said it can be installed on learners' smartphones and tablets. The group observed that using the app was advantageous because learners can work on it while offline. The group reflected as follows:

The target grade for this lesson is Grade 10. CK-12 app will be installed in the school computer lab so that learners can have access to them. Also, learners will have CK-12 app installed in their personal gadgets, i.e. smartphones, tablets, PCs, etc. This CK-12 app will be able to function offline so that those learners who cannot afford to buy data can use the app as well.

The group suggested they would use the CK-12 app to teach a lesson with the following objectives that they formulated:

1. The learners will learn to identify the heating and cooling curve of water.

2. The learners will learn to identify the apparatus used in the heating and cooling of water.

3. The learners will learn to describe the process of the heating and cooling curve of water.

4. The learners will learn to list the changes of state.

5. The learners will learn to relate the change of state to a change in temperature.

The group further reflected on the merits of using the simulation app by saying that it is interactive and allows learners to perform trials and errors, manipulate variables and develop science process skills. The group said:

The CK-12 app is similar to the actual lab as it allows learners to manipulate variables as they wish. This app is interactive because it doesn't assist learners with the experiment, but it allows learners to commit mistakes so that they can be able to identify the external factors that may cause the results to be inaccurate. Process skills to be developed are (not limited to) observing, communicating, classifying, inferring and predicting.

Similar to Group 3, Group 4 indicated that in order to ensure that learners would be able to make accurate measurements and engage in trial and error and trail and improvement exercises multiple times, they can use the EveryCircuit simulation application. The learners would use this app to build circuits. An example is provided in Figure 3.

Group 4 further indicated that the learners would conduct an experiment with the aim to "determine the relationship between the voltage and the rate at which charges moves past a fixed point in a circuit (current)" using the EveryCircuit app. The group suggested the use of the EveryCircuit app together with Excel to enable learners to draw graphs. The group reflected as follows:

What we also noticed was that the application does not represent data/results in the form of graphs. In this case, we also use Excel to help us represent data/results in the form of graphs.

The group provided an example of a table of results that the learners would draw in Excel (Figure 4). 


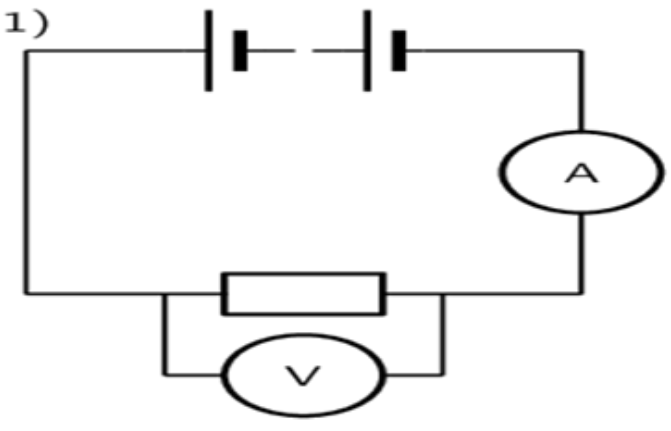

(a)

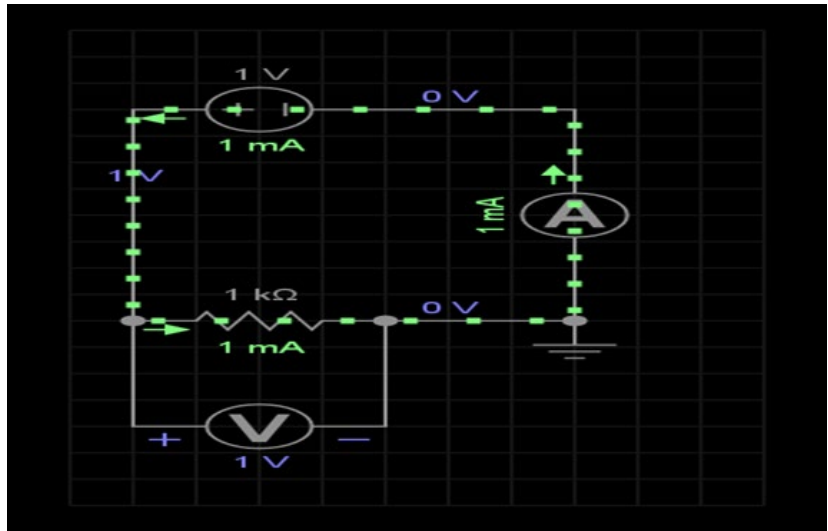

(b)

Figure 3. a) Circuit diagram and b) virtual circuit diagram

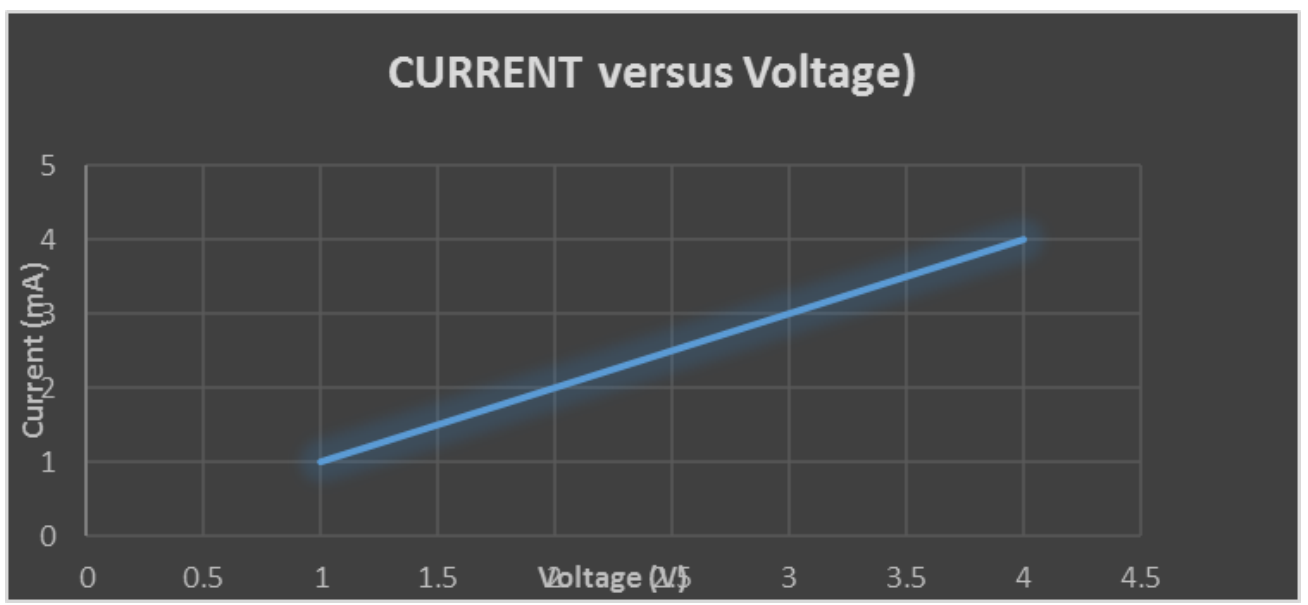

Figure 4. Current vs voltage graph

\section{Emerging Beliefs and Perceptions on Computational Thinking}

The final requirement of the computational thinkingIBPW integration exercise was for the participants to provide an open-ended reflection of their experiences. The emerging beliefs and perceptions were that computational thinking enables learners to develop computer literacy, engage in problem-solving and practise science process skills. Group 1 also realised that computational thinking could be employed as an instructional strategy. A reflection excerpt reads as follows:

While doing the experiment on this virtual lab, learners will be able to gain various ... skills that will not only help them in the classroom but in their lives as well. They will gain skills like navigation skills and co-ordination skills when they measure different lengths. They will also learn that there are various functions that you can use the computer for and that the computer and the internet are not only used for social media. It can also be used for academics to make teaching and learning easier and more efficient. Finally, it helps learners learn to use ICTs to solve various scientific problems and to gain scientific
knowledge.

In identifying a problem in IBPW implementation, Group 1 noticed that there are some lesson objectives for some topics in physical sciences that cannot be achieved without engaging learners in hands-on or virtual handson activities.

Although Group 2 did not provide a reflection at the end of the lesson planning, it seemed that they had emerging beliefs and perceptions on using IBPW computer-based activities to teach learners computational thinking and problem-solving. For Group 2, engaging learners in computational thinking was a way of making learners understand abstract concepts.

The reflections by Group 3 seemed to suggest that the experiences with the computational thinking exercise had helped them to know that there are ways to solve problems related to lack of materials and that they should develop problem-solving skills. The group said:

We have learnt that we can use computational thinking in our future physical sciences classrooms; even though there might be shortages 
of materials, there are still other methods we can use to facilitate the lesson. As teachers we should be resourceful and not rely on a single method of teaching, but we can use other methods, such as computational thinking, to allow learners to be creative thinkers.

In concluding their reflections, the participants in Group 3 realised that computational thinking had helped them to identify alternative instructional strategies to replace the ones that cannot be implemented effectively. In addition, they realised that computational thinking provides learners with opportunities to develop important skills such as exploration and creativity. The group said:

We learned that it is important to integrate computational thinking skills in our lessons in order to solve problems faster, enhance learner thinking skills and explore new ideas. Computational thinking allows us to be more creative and productive. It makes us explore and be aware of the world around us. It encourages students to pursue their own interest.

For Group 3, the use of a simulator was part of engaging in thought processes to formulate solutions that humans could implement with the aid of digital tools. The use of simulators was also regarded to be an effective way of reducing the lesson preparation time for teachers.

The participants in Group 4 had emerging beliefs and perceptions on the integration of computational thinking with IBPW that included the ability to be critical about the existing simulation applications and the ability to use other tools to make up for shortcomings. The group reflected as follows:

But, we can say that the application really needs some improvement. We are saying this because the application does not interpret or analyse the results. The application does not show graphs or even tables for the results.

The participants in Group 4 seemed to realise that simulators are useful teaching and learning tools that learners find easy and exciting to use. The group also seemed to think that the use of simulators facilitated the development of computational thinking for learners. The group said:

The computational thinking [EveryCircuit] makes the process of teaching and learning easier by that this application, firstly, ... is so easy to work with and everything is straightforward. Learners will be so happy to work with it because it has so many interesting features.
The participants also considered that the simulator that they used provided an authentic environment for learners to practise science process skills such as observation and manipulation. The group reflected as follows:

For example, in our project where we determine the relationship between the voltage and the current. As we manipulate/change the number of cells connected in the circuit, learners can see what happens to the current as the result; they will never forget the Ohm's law - current is directly proportional to the voltage. Both learning and teaching was facilitated.

For Group 4, simulators were considered to be alternative practical work environments that are less costly and provide accurate readings that can be used by learners to observe patterns and relationships.

\section{DISCUSSION}

The study set out to explore how preservice science teachers would use computational thinking as a problem-solving strategy when facilitating IBPW in multiple-deprived classrooms. Computational thinking was operationalised as thought processes aimed at formulating a problem and its solution(s) in ways that a computer and human can implement it, given the increasingly digitalised classroom environments (Wing, 2017). It was also recognised that IBPW can be based on activities that involve the use of computers and other digital tools (Akuma \& Callaghan, 2019). Conditions of multiple deprivation in science classrooms were regarded to be all unmet needs (Noble et al., 2013) necessary for effective teaching and learning and standing in the way of implementing innovative instructional strategies.

The participating preservice physical sciences teachers were aware of some of the conditions of multiple deprivation that inhibit the proper implementation of IBPW in science classrooms. They specifically mentioned the lack of laboratory materials and equipment and the use of poorly maintained, damaged equipment due to high purchase and replacement costs (Reid \& Shah, 2007). Participants also mentioned time constraints as one of the inhibitors of IBPW implementation (Kim \& Tan, 2011). Some of the participants identified the abstractness of some scientific concepts as a problem that could be solved by engaging learners in computational thinking processes.

Responding to how the participants used computational thinking for problem-solving when facilitating IBPW, four critical findings were made. First, for the participants to use computational thinking as a problem-solving tool for the effective implementation of IBPW, they made use of simulation apps that enable learners to engage in virtual hands-on activities. Yadav 
et al. (2014) emphasised the use of automation when using computational thinking to solve real-life problems. Automation may be made possible through the use of digital tools and Wing (2017) proposed that computational thinking should involve computers and machines.

Second, the participants engaged in some of the crucial computational thinking thought processes that included problem identification and problem decomposition. The groups defined conditions of multiple deprivation and further specified how the conditions became hindrances for the teaching and learning of certain topics. For example, lack of materials was further specified to lead to the inability by teachers and learners to conduct IBPW, failure to achieve some lesson objectives, and the ineffectiveness of instruments to take correct measurements. Breaking down the problem (problem decomposition) is an important step that should be taken before solutions can be formulated (Yadav et al., 2017). Studies have shown that teachers bemoan the lack of resources and other inhibiting factors as hindering the successful implementation of IBPW (Kidman, 2012; Kim \& Tan, 2011; Ramnarain \& Hlatswayo, 2018). There is a need for teachers to go beyond the noticing of challenges to finding solutions. Computational thinking is one of the tools that can be used by teachers to solve some teaching and learning problems for IBPW.

The third critical finding is that the participants suggested that learners should be engaged in computational thinking thought processes as a way of conducting IBPW. These thought processes include working with data, pattern recognition, pattern generalisation and abstraction. Wing (2017) presented computational thinking as one of the important

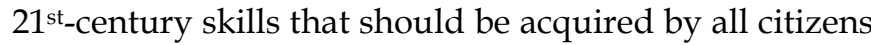
and not by people in computer science only. Yadav et al. (2017) indicated that there are some similarities between computational thinking and scientific inquiry. Therefore, as learners engage in scientific inquiry such as IBPW, they make use of thought processes that also define computational thinking. The integration of computational thinking and IBPW by the participants was used to provide authentic environments to aid learning. Integration of the two innovative strategies is important, especially since some teachers have been observed to use educational technologies for communication and administration only and not to provide meaningful teaching and learning experiences to learners (Ndlovu \& Meyer, 2019).

Fourth, as the participants engaged in the computational thinking exercise, they began to form important beliefs and perceptions on how to ensure successful implementation of IBPW in physical sciences. Beliefs and perceptions are important because they are used by teachers as resources and guide the process of teaching and learning (Cheng et al., 2016). These perceptions and beliefs include the realisation that virtual laboratories can be used to mitigate the lack of other expensive and dysfunctional materials and equipment used in practical work. Participants realised that the use of virtual laboratories ameliorated challenges related to the limited time for laboratory preparation and cleaning up after experiments. As a result, participants were able to (i) make use of simulation apps that enable learners to engage in virtual hands-on activities; (ii) use computational thinking thought processes to solve challenges in multipledeprived classrooms; and (iii) propose that learners should be engaged in computational thinking as they conduct IBPW.

\section{CONCLUSION}

Computational thinking enabled the participating preservice physical sciences teachers to solve challenges that inhibit the successful implementation of IBPW. One of the ways found to solve the challenges was to integrate computational thinking and IBPW activities. Participants developed important beliefs and perceptions on the use of computational thinking and IBPW, which can serve as innovative instructional strategies. The limitation of the study is that the lesson plans and solutions suggested were not implemented in real classrooms. Therefore, a further study is recommended in which preservice teachers' experiences of using computational thinking to solve IBPWimplementation problems are conducted in real classrooms.

\section{ACKNOWLEDGEMENTS}

The study was supported by the Thuthuka Funding Instrument (NRF Rating Track); Reference: TTK180505326403.

\section{REFERENCES}

Akuma, F. V., \& Callaghan, R. (2019). Teaching practices linked to the implementation of inquiry-based practical work in certain science classrooms. Journal of Research in Science Teaching, 56(1), 64-90. https:/ / doi.org/10.1002/tea.21469

Andriessen, D. (2007). Combining design-based research and action research to test management solutions. Paper presented at the 7th World Congress Action Learning, Action Research and Process Management, Groningen, 22-24 August, pp. 1-8.

Cheng, P. Y., Talib, O., \& Othman, A. (2016). Science teaching: Perceptions, attitudes and instructional practices. Jurnal Pendidikan Sains and Matematik Malaysia, 6(2), 1-17. Retrieved from https:/ / ejournal.upsi.edu.my/index.php/ JPSMM/article/view/2163 
Chikoko, V. (2018). The nature of the deprived context: Leadership that works in deprived school contexts of South Africa. Nova Science Publishers.

Collato, D. C., Dresch, A., Lacerda, D. P., \& Bentz, I. G. (2018). Is action design research indeed necessary? Analysis of synergies between action research and design science research. Syst. Pract. Action Research, 31, 239-267. https://doi.org/10.1007/s11213-0179424-9

Djambong, T., \& Freiman, V. (2016). Task-based assessment of students' computational thinking skills developed through visual programming or tangible coding environments. 13th International Conference on Cognition and Exploratory Learning in Digital Age (CELDA), Mannheim, Germany, 28-30 October, pp. 41-51.

Dunn, J., \& Ramnarain, U. (2020). The effect of simulation-supported inquiry on South African natural sciences learners' understanding of atomic and molecular structures. Education Science, 10(10), 280. https:/ / doi.org/10.3390/educsci10100280

Hestness, E., Ketelhut, D. J., McGinnis, J. R., \& Plane, J. (2018). Professional knowledge building within an elementary teacher professional development experience on computational thinking in science education. Journal of Technology and Teacher Education, 26(3), 411-435. Retrieved from https: / / www.learntechlib.org/primary/p/181431

Kazimoglu, C., Kiernan, M., Bacon, L., \& MacKinnon, L. (2012). Learning programming at the computational thinking level via digital game-play. Procedia Computer Science, 9, 522-531. https://doi.org/10.1016/j.procs.2012.04.056

Kidman, G. (2012). Australia at the crossroads: A review of school science practical work. Eurasia Journal of Mathematics, Science and Technology Education, 8(1), 35-47. https:/ / doi.org/10.12973/eurasia.2012.815a

Kim, M., \& Tan, A. L. (2011). Rethinking difficulties of teaching inquiry-based practical work: Stories from elementary pre-service teachers. International Journal of Science Education 33(4), 465-486. https:/ / doi.org/10.1080/09500691003639913

Magnusson, S. J., Borko, H., \& Krajcik, J. S. (1999). Nature, sources, and development of pedagogical content knowledge for science teaching. In J. GessNewsome \& N. Lederman (Eds.), Examining pedagogical content knowledge (pp. 95-132). Kluwer Press. https:/ / doi.org/10.1007/0-306-47217-1_4

Maringe, F., Masinire, A., \& Nkambule, T. (2015). Distinctive features of schools in multiple deprived communities in South Africa: Implications for policy and leadership. Educational Management Administration and Leadership, 43(3), 363-385. https:/ / doi.org/10.1177/1741143215570303
Mouza, C., Yang, H., Pan, Y. C., Ozden, S. Y., \& Pollock, L. (2017). Resetting educational technology coursework for pre-service teachers: A computational thinking approach to the development of technological pedagogical content knowledge (TPACK). Australasian Journal of Educational Technology, 33(3), 61-76. https:/ / doi.org/10.14742/ajet.3521

Mulhall, P. J., Berry, A., \& Loughran, J. (2003). Frameworks for representing science teachers' pedagogical content. Asia-Pacific Forum in Science Learning and Teaching, 4(2), Article 2, 1-25.

Ndlovu, M., \& Meyer, D. (2019). Readiness of teachers to teach mathematics with technology: A case study of a school in Gauteng. The 63 ${ }^{\text {rd }}$ ICET World Assembly, Johannesburg, pp. 188-197.

Noble, M., Zembe, W., Wright, G., \& Avenell, D. (2013). Multiple deprivation and income poverty at small area level in South Africa in 2011. SASPRI.

Printy, S. M. (2010). How principals influence instructional practice: Leadership levers. In W.K. Hoy \& M. DiPaola (Eds.), Analyzing social contexts: Influences of principals and teachers in service of students (pp. 71-102). Information Age Publishing.

Ramnarain, U., \& Hlatswayo, M. (2018). Teacher beliefs and attitudes about inquiry-based learning in a rural school district in South Africa. South African Journal of Education, 38(1), 1-10. https://doi.org/ $10.15700 /$ saje.v38n1a1431

Reid, N., \& Shah, I. (2007). The role of laboratory work in university chemistry. Chemistry Education Research and Practice, 8(2), 172-185. https://doi.org/ 10.1039/B5RP90026C

Shulman, L. (1987). Knowledge and teaching: Foundations of the new reform. Harvard Educational Review, 57(1), 1-22. https://doi.org/10.17763/ haer.57.1.j463w79r56455411

Thanh, N. C., \& Thanh, T. T. L. (2015). The interconnection between interpretivist paradigm and qualitative methods in education. American Journal of Educational Science, 1(2), 2015, 24-27.

Tsakeni, M. (2018). Inquiry-based practical work in physical sciences: Equitable access and social justice issues. Issues in Educational Research, 28(1), 187-201. Retrieved from http://www.iier.org.au/ iier28/tsakeni.pdf

Weintrop, D., Beheshti, E., Horn, M., Orton, K., Jona, K., Trouille, L., \& Wilensky, U. (2016). Defining computational thinking for mathematics and science classrooms. Journal of Science Education and Technology, 25(1), 127-147. https://doi.org/ 10.1007/s10956-015-9581-5

Wing, J. M. (2006). Computational thinking. Communications of the ACM, 49(3), 33-35. https:// doi.org/10.1145/1118178.1118215 
Wing, J. M. (2017). Computational thinking's influence on research and education for all. Italian Journal of Educational Technology, 25(2), 7-14. https:/ / doi.org/ 10.17471/2499-4324/922

Yadav, A., Mayfield, C., Zhou, N., Hambrusch, S., \& Korb, J.T. (2014). Computational thinking in elementary and secondary teacher education. ACM
Trans. Comput. Educ., 14(1), Article 5. https:/ / doi.org/10.1145/2576872

Yadav, A., Stephenson, C., \& Hong, H. (2017). Computational thinking for teacher education. Communications of the ACM, 60(4), 55-62. https://doi.org/10.1145/2994591

\section{http://www.ejmste.com}

